\title{
Sustaining Togetherness; Family Engagement in Tuberculosis Prevention in Children Living in Tuberculosis Households in Indonesia
}

\author{
Windy Rakhmawati ${ }^{1 *(\mathbb{D})}$, Kittikorn Nilmanat $^{2}{ }^{(\mathbb{D})}$, Urai Hatthakit ${ }^{3}$ (i) \\ ${ }^{1}$ Department of Pediatric Nursing, Faculty of Nursing, Universitas Padjadjaran, Bandung, Indonesia; ${ }^{2}$ Department of Adult and \\ Elderly nursing, Prince of Songkla University, Songkhla, Thailand; ${ }^{3}$ Department of Nursing Administration, Prince of Songkla \\ University, Songkhla, Thailand
}

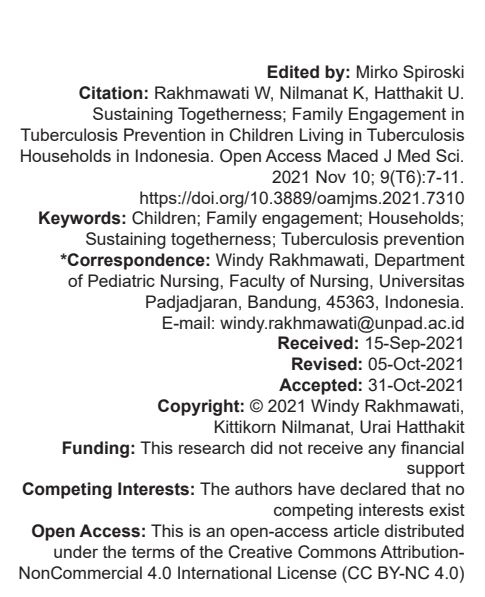

\begin{abstract}
BACKGROUND: Preventing tuberculosis (TB) in children needs the family to be engaged; however, limited studies about how the family engages in TB prevention.

AIM: This aimed of study was to develop the process of family engagement in TB prevention for children with household contact of TB patient.

METHODS: Guided by Straussian grounded theory, we developed a substantive theory from 14 primary caregivers in West Java-Indonesia as the key participants of families whose child $\leq 5$ years old received TB screening and preventive therapy, and have had an adult in the household with active TB diagnosis. Data were collected by in-depth interviews and analyzed by coding procedures.

RESULTS: Sustaining togetherness aimed to maintain the children's health, which underpinned three main stages that consisted of "moving from fear to realization," "making the family's collective decision," and "holding on together." CONCLUSION: Implications for nursing practice in providing optimum care of preventing TB among children through engagement of family.
\end{abstract}

\section{Introduction}

Childhood tuberculosis (TB) is considered as an urgent health problem worldwide as TB is responsible as a cause of child mortality and morbidity. In 2018, TB among children were estimated at about $11 \%$ of 7 million new TB cases and 210,000 children died because of TB [1]. The TB cases among children vary widely across different countries and the third highest TB burdened country is Indonesia. In Indonesia, 7\% of new TB cases were children [1]. Furthermore, of the 33 provinces in Indonesia, West Java Province had the highest proportion of child TB cases among all TB cases [2]. Apart from high prevalence and high mortality rate, the World Health Organization (WHO) estimated that only $13 \%$ of 1.3 million children $\leq 5$ years old with household contact received TB preventive treatment.

The family plays a crucial role in TB prevention and control. The family should engage in a TB prevention program. Indonesia derives from the WHO recommendations about TB prevention for children, which includes Bacillus Calmette-Guérin vaccination, childhood contact screening, and management that includes tuberculin skin test (TST), chest $X$-rays (CXR), isoniazid preventive therapy (IPT), and infection control [3]. However, the TST, CXR, and IPT are only available in the secondary level of health-care services which include the community lung clinics and regional general hospitals.

Several studies reported that successful family engagement in TB prevention significantly protected children from TB disease [4], [5]. However, it was reported that the level of family engagement in Indonesia was low or poor and challenge for health-care providers [6], [7]. Limited studies that have reported on how families completely engage in preventing their children from other family members who are infected with TB, and the psychosocial process of families to cope and deal with their barriers.

However, understanding the overall process of family engagement is needed. Therefore, this study aimed to develop a substantive theory of how the process of family engage in TB prevention for children 
living in households where there are one or more of family members infectious TB. This study has a significant implication for nursing practice to prevent TB in children. Thus, the purpose of this study is to develop a process of family engagement in prevention of TB for children that are generated from grounded theory methodology.

\section{Methods}

\section{Study design}

Straussian Grounded Theory methodology was used to conduct this study. This methodology provides "a true-and-set of procedures for constructing theory from data" [8]. It helped the researcher to generate the particular process pattern of family engagement in TB prevention for children living in active TB households.

\section{Sample and settings}

Two sampling approaches were applied from the community lung clinic-Bandung, Indonesia, and continued by visiting the participants' home. Initially, we used a purposive sampling approach to recruit participants who met the inclusion criteria including families who lived in the same households with a child $\leq 5$ years old, their child received TB screening and adhered to IPT, had an adult with an active TB diagnosis. The key participants were the primary caregivers who took the main responsibility of taking care of their children and who voluntarily participated. To gather more data to saturate the categories, theoretical sampling was then conducted to select further participants. Saturation occurred after the final number of participants was 14 primary caregivers.

\section{Data collection}

In-depth interviews were used to collect data during period of December 2016 to July 2017. For each participant, interviews were conducted 2 -4 times in the family's home. It took 40-90 min for each interview. All interviews were tape-recorded and transcribed verbatim before being translated into English. The researcher made field notes to record immediate responses to the interaction as well as the non-verbal behaviors of the family during the interview that do not present themselves in the transcription.

\section{Data analysis}

Coding procedures from Strauss and Corbin were used to analyze data that consist of open coding, axial coding, and selective coding. A constant comparative analysis was also used as a simultaneous process with data collection that included comparing codes and categories to one another for the similarities and differences of them. Then, the researchers related the categories to other categories by the paradigm model consisting of conditions, action/interactional strategies, and consequences [8], [9]. Finally, the researcher selected one dominant core category which was abstract enough to integrate into the other categories.

\section{Ethical consideration}

This study obtained the ethical approval from the Ethics Committee of the Faculty of Nursing, Prince of Songkla University, Thailand, with number MOE0521.1.05/2580. Verbal and written informed consent from all participants was also obtained. To maintain the confidentiality, anonymity was applied while due to the awareness of TB stigma the researcher used an informal dress and public transportation to visit participants at their come to prevent the potential social and emotional risk.

\section{Results}

The total number of participants was 14 Muslim primary female caregivers. However, five participants were engaging in preventing TB in children while being a TB patient. All participants are Sundanese people and their age ranged between 22 and 43 years.

"Sustaining togetherness" was identified as the core category and as the basic social psychological process. This process was divided into three main categories: (1) Moving from fear to realization, (2) making the family's collective decision, and (3) holding on together (Figure 1).

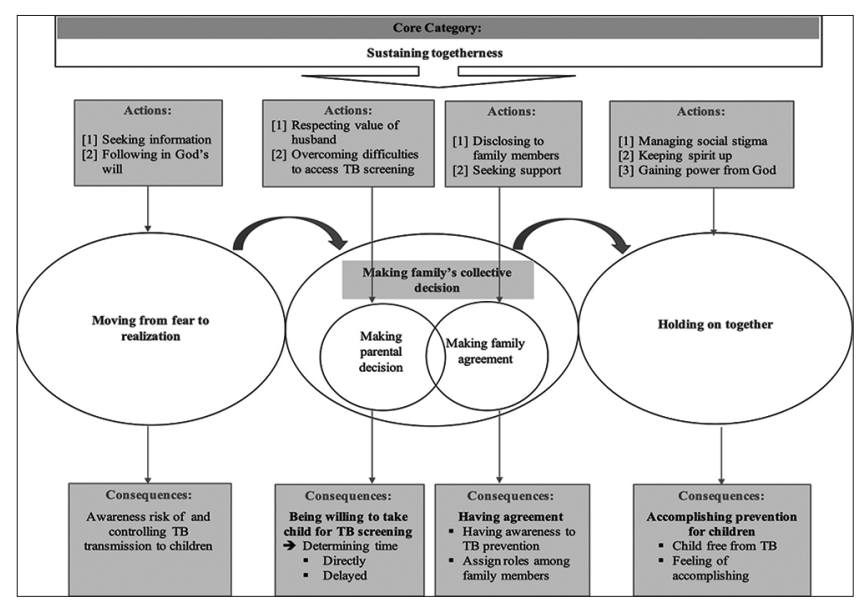

Figure 1. The process of family engagement in TB prevention for children living in active TB households: Sustaining togetherness to achieve the child's health 


\section{Moving from fear to realization}

Knowing a TB diagnosis led the family feels fearful of TB. They were fearful that TB would be spread to their children or others.

My TB condition was severe. I could not do anything. I wondered whether my children would develop TB, like me ... I was afraid that it (TB) would infect my youngest child (F6)

Fear of stigma was also reported as the families' reactions when knowing of a TB diagnosis by some key participants. They would then be blamed as the cause of transmission and excluded from social life. The key participants sought information about TB prevention from the nurses.

Nurse said that because my daughter's age was $<5$ years old, she had a high risk to be infected. Then, she should be given a prophylaxis (IPT) for 6 months, for prevention. I am afraid for being discrimination because TB in the society. (F3)

\section{Making the family's collective decision}

This second stage was the period of time for the family to come together and begin to sustain the togetherness of the family. The mothers involved their family members as a unit in two steps; (a) making a parental decision and (b) making a family agreement.

\section{Making a parental decision}

The step of making a parental decision began when the mothers attempted to involve their husbands by valuing their husbands as the head of family, telling them, and communicating to them the TB transmission and prevention. This helped their husbands to understand and realize the risk of TB transmission and work together with their wives as a parent to prevent TB.

I told my husband carefully what we had to do. When I talked to him, my aunty helped me to explain to my husband. He could understand and support me. We were worried that my TB would be transmitted to my child. (F1)

\section{Making a family agreement}

The step of making a family agreement began when the result of TB screening of children $\leq 5$ years old reported that the children did not have TB disease and should receive TB preventive medicines. Therefore, an agreement was come to with all the family members, including the parents, children, other family members who had TB, and/or grandparents.

As one participant described that her family had a grandmother as the TB patient; however, she felt that since the grandmother was the oldest person in the household, she should be respected and disclosed about TB prevention carefully:

We (participant and her husband) informed her (grandmother) and asked her to use a mask all the time at home. We told her to open her room in the morning. She was willing to do that. Thus, we were committed to TB prevention for our children. (F2)

\section{Holding on together}

This stage refers to the way that all the family members used to sustain their togetherness to continue their TB prevention measures. Therefore, the family held on together to overcome their emotional constraints by managing social stigma, keeping spirits up, and gaining power from God. Concerning the management of social stigma, most families tried to cope with stigma by keeping TB a secret, by isolating themselves, or ignoring, or convincing as well as explaining to others.

The important thing is that my family and I are healthy. The important thing is I have been treated because I want to be healthy. If they did not want to talk with me, it is up to them. (F5)

As a big family, the family support from all family members including grandparents and relatives was essential for the ability of the families to enhance their spirit and continue to engage in TB prevention measures.

The main need was a support to encourage our spirits. My father, mother, all my brothers, and sisters always gather in my house make us have strong spirits. (F5)

Another action was gaining power from God, which refers to getting closer to God using religious beliefs. Therefore, they felt that they had to accept their suffering and attempt to prevent TB from being transmitted to their children as well as praying to Allah to ask for good health and the result of this was to put themselves into Allah's (God) hands.

Sometimes, I felt I did not have any spirit and my husband too. May be the tested on our family. We have to be strong. We believe because health comes from God. (F4)

\section{Discussion}

Sustaining togetherness of the family is the substantive theory that was developed in this study. The major task of families in this theory was to work together and all family members helped each other with the aim to prevent TB in the children living in active TB households to maintain the health of their children. 
Most families expressed their emotional reactions to the TB diagnosis that included fear of transmitting TB to their child and stigma. Those fears stimulated them to become aware and realize the need to be involved in TB prevention as a result of maintaining their child's health by seeking information about TB transmission and prevention. Sufficient information contributed to enhancing the knowledge of the participants, which, in turn, increased their awareness and realization of the risk of TB transmission [10], [11], [12].

In this study, the mother was the family caregiver who responsible for taking cares of children. In addition, the Indonesian family values influenced the decision-making process which was related to the gender role in child care, closeness kinship relationships, and hierarchical relationships within the family that emphasized the respect of the younger to older people and the wives to husbands on the family decisions to prevent TB transmission. Indonesian families consider that the wife is the main family member who takes responsibility for all household tasks and the children's needs. However, the husband, as head of the family, should be respected by the wife and tell him everything [13], [14].

Good communication for decision making among family members was also essential. It was demonstrated by disclosure to the spouse and other family members concerning the diagnosis of TB, its transmission, and prevention for their children. The aim of disclosing was to involve all family members in TB prevention for the children. Involving all members, as a close circle of entrusted family, maintains the cohesiveness of a family to achieve the greatest health of all family members as a whole [15], [16], [17].

Sufficient information also contributed to the agreement of all family members to be involved in TB prevention for their children. Therefore, nurses should provide adequate information in decision making to facilitate the family members as a unit to be involved in TB prevention. Clarifying a family's perception to the treatment by health professionals was fundamental for successful treatment which can raise the awareness of a family to the treatment [18]. The holding on together among family members emerged as the last stage and in the process of family engagement. This concept was similar with the concept of collaboration. The context of collaboration was extended to other family members including parents, children, grandparents, and relatives. This reflects the values of Indonesian families that have good close relationships among the family members, grandparents, and relatives as a large family.

During the last stage, the family might encounter the emotional constraints from caregivers-self, children, TB patients, and communities. These emotional constraints may reduce their motivation and willingness in the continuity of their togetherness in TB prevention for their children. Therefore, the family members helped each other to improve their commitment to maintain their togetherness and accomplish all stages to achieve their child's health. The finding validates the importance of collaboration and commitment with engagement in TB prevention for children. Holding on together reflected that all family members collaborated and worked together to achieve the same goal which was to have a healthy child. Support from all family members was also essential and reflected the close relationship [19] as a large family. The role of the family was to give support which included giving love, encouragement, psychosocial support, and reminding the patient [17].

The limitations in this study were the primary caregiver in that all primary caregivers were mothers, and the religion of all the families was Islam. The lack of diversity in terms of family relationship status, gender, and religion, may have influenced the diversity of experiences of families to engage in preventing TB.

\section{Conclusion}

The findings of this study revealed that the Indonesian family values in Indonesia strongly influenced the family engagement process and contributed to the strategies families used and consequences that resulted in each stage. This study has implications for nursing particularly the community nursing to control the increase of TB disease among children by providing the optimum care of childhood TB prevention. Furthermore, the stages in this study can be taught to other families to help them in the engagement of preventing transmission of TB to children living in active TB households. Therefore, nursing interventions should be developed based on the conditions that include family values, religious beliefs, and specific needs of the family.

\section{Acknowledgments}

The authors would like to thank the Indonesian Ministry of Education and Culture, the Graduate School of Prince of Songkla University, the Universitas Padjadjaran, and the lung clinic Bandung-Indonesia.

\section{References}

1. World Health Organization. Global Tuberculosis Report 2019 Geneva: World Health Organization; 2019.

2. Pusadatin, Tuberkulosis: Temukan, Obati Sampai Sembuh Jakarta: Kementerian Kesehatan RI; 2015. https://doi. org/10.35568/abdimas.v2i1.338 
3. Ministry of Health of Republic Indonesia. Petunjuk Teknis Manajemen TB anak [Technical Manual of Childhood TB Management]. Jakarta, Indonesia: Ministry of Health of Republic Indonesia; 2016.

4. Garie KT, Yassin MA, Cuevas LE.Lack of Adherence to Isoniazid Chemoprophylaxis in Children in Contact with Adults with Tuberculosis in Southern Ethiopia. PLoS One. 2011;6(11):e26452. https://doi.org/10.1371/journal. pone.0026452

PMid:22069451

5. Zelner JL, Murray MB, Becerra MC, Galea J, Lecca L, Calderon R, et al. Bacillus Calmette-Guerin and isoniazid preventive therapy protect contacts of patients with tuberculosis. Am J Respir Crit Care Med. 2014;189(7):853-9. https://doi. org/10.1164/rccm.201310-1896oc

\section{PMid:24592878}

6. Supinganto A, Metri IK, Supriyanto S. Gambaran peran keluarga dalam bidang kesehatan terhadap pencegahan penularan TB (tuberculosis) paru di kabupaten Lombok Barat tahun 2013 [Scientific articles depiction of the role of the family for preventing infection of TB (Tuberculosis) lung disease in. Penelit UNRAM. 2014;18(1):43-9. https://doi.org/10.25157/jkg. V2i2.4536

7. Herawati I, Ruslami R, Yamin A. Case study of non-adherence of household contacts toward tuberculosis screening. J Keperawatan Padjadjaran. 2013;1(2):63-71.

8. Strauss CJ. Basics of Qualitative Research. $4^{\text {th }}$ ed. California: Sage; 2015.

9. Birks M, Mills J. Grounded Theory: A Practical Guide. London: Sage; 2012.

10. Gerrish K, Naisby A, Ismail M. Experiences of the diagnosis and management of tuberculosis: a focused ethnography of somali patients and healthcare professionals in the UK. J Adv Nurs. 2013;69(10):2285-94. https://doi.org/10.1111/jan.12112 PMid:23421790

11. Sulistyono RE, Susanto T, Tristiana RD. Patients experience and perception in preventing tuberculosis transmission in rural areas: A qualitative research. J Keperawatan Padjadjaran.
2020;8(1):21-30. https://doi.org/10.24198/jkp.v8i1.1288

12. Juniarti N, Evans D. A qualitative review: The stigma of tuberculosis. J Clin Nurs. 2011;20(13-14):1961-70. https://doi. org/10.1111/j.1365-2702.2010.03516.x

PMid:21040040

13. Amar SC. Gunem catur in the Sunda region of West Java Indigenous Communication on MAC Plant Knowledge and Practice within the Arisan in Lembang, Indonesia. Leiden University; 2010.

14. Piercy FP, Soekandar A, Limansubroto CD, Davis SD. Indonesian families. In: McGoldrick GP, Giordano JM, editors. Ethnicity and Family Therapy. $3^{\text {rd }}$ ed. London: The Guilford; 2005. p. 332-38.

15. Kim-Godwin YS, Bomar PJ. Family health promotionl. In: Kaakinen JR, Gedaly-Duff V, Coehlo DP, Hanson SM, editors. Family Health Care Nursing: Theory, Practice, and Research. $4^{\text {th }}$ ed. Philadelphia, PA: Sage; 2010. p. 207-34. https://doi. org/10.1177/1074840710383274

16. Ayisi JG, van't Hoog AH, Agaya JA, Mchembere W, Nyamthimba PO, Muhenje $\mathrm{O}$, et al. Care seeking and attitudes towards treatment compliance by newly enrolled tuberculosis patients in the district treatment programme in rural western Kenya: A qualitative study. BMC Public Health. 2011;11(515):110. https://doi.org/10.1186/1471-2458-11-515

17. Paz-Soldán VA, Alban RE, Jones CD, Oberhelman RA. The provision of and need for social support among adult and pediatric patients with tuberculosis in Lima, Peru: A qualitative study. BMC Health Serv Res. 2013;13(1):290. https://doi. org/10.1186/1472-6963-13-290 PMid:23899353

18. Hino P, Takahashi RF, Bertolozzi MR, Villa TC, Egry EY. Family health team knowledge concerning the health needs of people with tuberculosis. Rev Lat Am Enfermagem. 2012;20(1):44-51. https://doi.org/10.1590/s0104-11692012000100007 PMid:22481720

19. da Silva MV, dos Santos MA, Almeida FA. Experiences of caregivers of children. Rev Esc Enferm USP. 2014;48(2):39-45. https://doi.org/10.1590/s0080-623420140000800007 